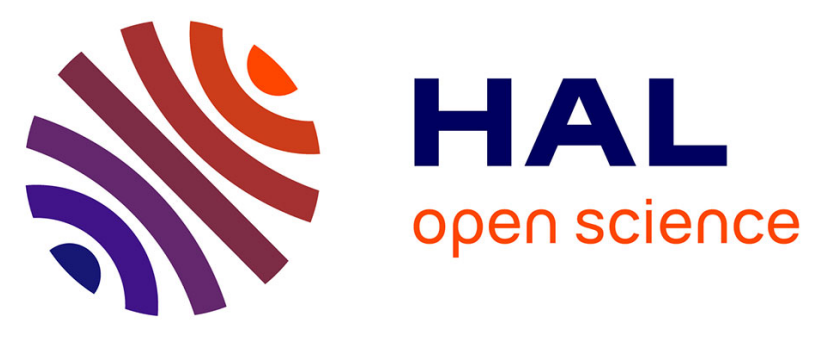

\title{
Reinvestigation of the synthesis of "covalent-assembly" type probes for fluoride ion detection. Identification of novel 7-(diethylamino)coumarins with aggregation-induced emission properties
}

Valentin Quesneau, Benoît Roubinet, Pierre-Yves Renard, Anthony Romieu

\section{To cite this version:}

Valentin Quesneau, Benoît Roubinet, Pierre-Yves Renard, Anthony Romieu. Reinvestigation of the synthesis of "covalent-assembly" type probes for fluoride ion detection. Identification of novel 7(diethylamino)coumarins with aggregation-induced emission properties. Tetrahedron Letters, 2019, 60 (48), pp.151279. 10.1016/j.tetlet.2019.151279 . hal-02320124

HAL Id: hal-02320124

https://hal.science/hal-02320124

Submitted on 21 Dec 2021

HAL is a multi-disciplinary open access archive for the deposit and dissemination of scientific research documents, whether they are published or not. The documents may come from teaching and research institutions in France or abroad, or from public or private research centers.
L'archive ouverte pluridisciplinaire HAL, est destinée au dépôt et à la diffusion de documents scientifiques de niveau recherche, publiés ou non, émanant des établissements d'enseignement et de recherche français ou étrangers, des laboratoires publics ou privés.

\section{(ㄷ)(1) $\$$}

Distributed under a Creative Commons Attribution - NonCommerciall 4.0 International 


\title{
Reinvestigation of the synthesis of "covalent-assembly" type probes for fluoride ion detection. Identification of novel 7-(diethylamino)coumarins with aggregation- induced emission properties
}

\author{
Valentin Quesneau ${ }^{\mathrm{a}}$, Benoît Roubinet ${ }^{\mathrm{b}}$, Pierre-Yves Renard ${ }^{\mathrm{b}}$, Anthony Romieu, ${ }^{\mathrm{a},{ }^{*}}$ \\ ${ }^{a}$ ICMUB, UMR 6302, CNRS, Univ. Bourgogne Franche-Comté, 9, Avenue Alain Savary, 21078 Dijon cedex, France \\ ${ }^{b}$ Normandie Univ, UNIROUEN, INSA Rouen, CNRS, COBRA (UMR 6014), IRCOF, 1 Rue Tesnières, 76821 Mont-Saint-Aignan Cedex, France
}

\section{ARTICLE INFO}

ABSTRACT

Article history:

Received

Received in revised form

Accepted

Available online

\section{Keywords:}

Aggregation-induced emission (AIE)

Coumarin

Covalent-assembly

Fluorescent probe

\begin{abstract}
An unprecedented C-3 functionalization of 4-(diethylamino)salicylaldehyde through a FriedelCrafts type alkylation reaction has been discovered during the synthesis of "covalent-assembly"based fluorescent probes for detection of fluoride ions. The resulting Friedel-Crafts adduct was successfully used for the preparation of two novel 8-substituted 7-(diethylamino)coumarin dyes. The photophysical study of these fluorophores has enabled us to highlight their remarkable aggregation-induced emission (AIE) properties characterized by a yellow-orange emission of aggregates in water. Therefore, 4-(tert-butyldimethylsilyloxy)benzyl substituent was identified as a novel AIE-active moiety which could be seen as a possible alternative to popular tetraphenylethylene (TPE).
\end{abstract}

* Corresponding author. Tel.: +33-3-80-39-36-24; e-mail: anthony.romieu@u-bourgogne.fr. 


\section{Introduction}

Among the various classes of organic-based fluorophores currently used for the construction of small molecule fluorescent chemosensors/chemodosimeters, coumarin derivatives figure prominently because of several valuable features including: (1) convenient synthetic accessibility, (2) good structural flexibility, (3) valuable spectral features (large Stokes shift and high fluorescence quantum yield), (4) easy modulation of their fluorescence properties through the implementation of different photophysical processes (e.g., PeT, ICT, FRET, ...) and/or protection-deprotection of an optically tunable amino or hydroxyl group introduced at the C-7 position and (5) low toxicity [1]. Consistently seeking to optimize the fluorogenic response (mainly, intensometric detection mode) arising from selective interaction/reaction of the coumarin-based probe with its supposed target (bio)analyte, a new probe design principle namely the "covalent-assembly" approach has recently emerged $[2,3]$. This cutting-edge strategy is based on in situ formation of a fluorophore from a non-fluorescent compound (also known as caged precursor) and through an effective intramolecular reaction triggered/catalyzed by the species to be detected. The fundamental feature of this approach is that it guarantees, in theory at least, a "turn-on" fluorimetric signal from a zero background, hence an optimal detection sensitivity. In this area, pioneering works of the Swager (2003) [4] and Anslyn (2005) groups [2a], on the fluorescent detection of fluoride anions and divalent heavy metal cations respectively, are based on in situ formation of 7-(diethylamino)coumarin (DEAC) derivatives through lactonisation or Heck-type cyclization reactions. Since these early remarkable achievements, more than 50 examples of "covalent-assembly" type probes for the detection of a wide range of analytes including biothiols, enzymes, metal cations and ROS/RNS, have already been published [5]. In all these cases, creation of blue-green emitting 7-dialkylamino/7-hydroxy-(2imino)coumarins or related fluorophores through lactonisation or Pinner cyclization reactions, is the keystone of the sensing mechanism (Fig. 1).

In the specific case of such reaction-based chemodosimeters devised for the selective sensing of fluoride ions whose detection/quantification in drinking or surface water is very important for public health, the analyte-responsive caged precursor is a $O$-protected 2-(dialkylamino)-4hydroxycinnamonitrile (or cinnamate ester) derivative and the phenol is masked as a tert-butyldimethylsilyl (TBDMS) or tertbutyldiphenylsilyl (TBDPS) ether (Fig. 1). The direct linkage of this triggering unit to the phenol moiety may negatively affect probe properties such as poor stability and slow response time. By analogy with some colorimetric, fluorescent or chemiluminescent probes recently published in the literature [6], a self-immolative spacer can be used to circumvent these possible issues. In this context, we wished to explore the synthesis and fluorogenic reactivity (towards fluoride ions) of next-generation "covalent-assembly" type probes that incorporate a selfimmolative para-hydroxybenzyl alcohol (PHBA) linker [5j, 7]. During the course of this work, we have highlighted an unexpected $\mathrm{S}_{\mathrm{E}} \mathrm{Ar}$ reaction leading to regioselective C-3 benzylation of 4-(diethylamino)salicylaldehyde. Since this type of building blocks is frequently used as starting material for the synthesis of coumarins, we next considered the Knoevenagel condensation between this 2-hydroxybenzaldehyde derivative and C-nucleophiles (i.e., malononitrile and benzothiazole-2acetonitrile) to produce novel DEAC-based fluorophores.

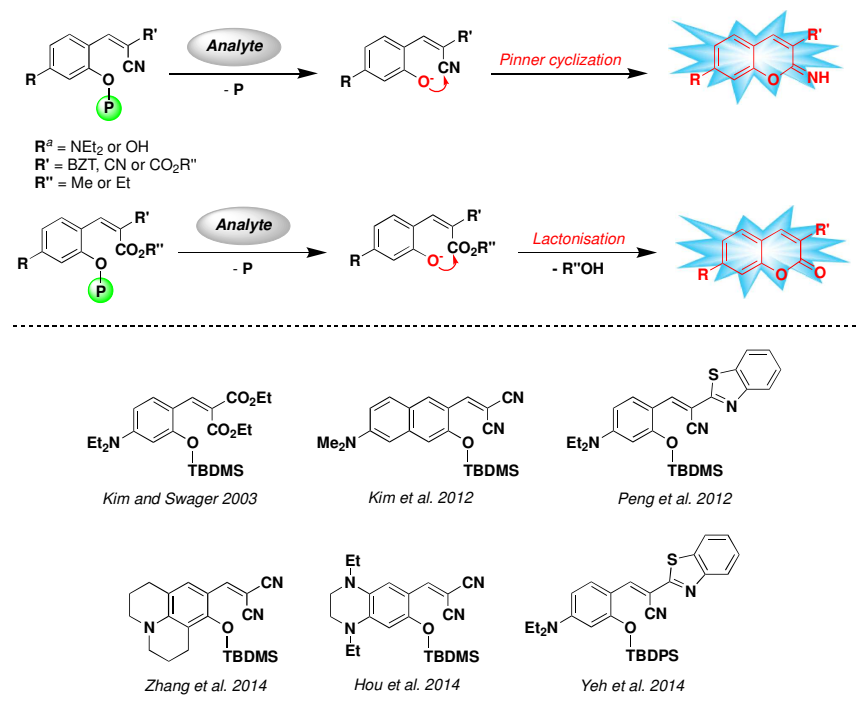

Fig. 1. (Top) "Covalent-assembly" probe design principle applied to fluorogenic detection of (bio)analytes through in situ synthesis of 7dialkylamino/7-hydroxy-2-iminocoumarins or 7-dialkylamino/7hydroxycoumarins; (bottom) examples of "covalent-assembly" type probes for $\mathrm{F}^{-}$detection reported in the literature $(\mathrm{BZT}=2$-benzothiazolyl, TBDMS = tert-butyldimethylsilyl, TBDPS = tert-butyldiphenylsilyl) [4, 5f, 5i, 5k, 5n]. aPlease note: fused julolidine, 4-dimethylaminophenyl and 1,4diethylpiperazine fragments are also frequently used in the design of such "caged" precursors, to red-shift spectral features of in situ formed coumarin.

In this Letter, in the course of our research on self-immolative linker based second generation "covalent-assembly" probes for fluoride ions, we report our findings on the unusual reactivity of 4-(diethylamino)salicylaldehyde towards 4-(tertbutyldimethylsilyloxy)benzyl bromide. This unprecedented reaction led us to consider the preparation and photophysical characterization of novel DEAC-based fluorophores. A comparative study of their spectral features with those of parent DEAC derivatives lacking a C-8 substituent, and conducted in different solvents (aq. buffers, DMSO and EtOH), has put in evidence an expected added value for these coumarin-based fluorophores, namely aggregation-induced emission properties.

\section{Results and discussion}

The vast majority of coumarin-based "covalent-assembly" type probes reported in the literature (see Fig. 1 for the general structure), are readily prepared via a well-established two-step process: (1) protection of the phenol group of salicylaldehyde derivative (mostly, 2-OH of 4-(diethylamino)salicylaldehyde or 2,4-dihydroxybenzaldehyde) with the selected trigger-recognition unit and subsequent (2) Knoevenagel condensation with malononitrile or related C-nucleophiles. In cases where a selfimmolative spacer is used to connect salicylaldehyde and recognition moiety, step (1) is often a $2-O$-alkylation reaction performed with a benzyl bromide derived from PHBA. To the best of our knowledge, this latter strategy was never applied to the design of fluoride-sensitive caged precursors of coumarins and TBDMS or TBDPS moiety is always directly attached to the phenol oxygen atom of salicylaldehyde derivative (Fig. 1) [4, 5f, $5 \mathrm{i}, 5 \mathrm{k}, 5 \mathrm{n}]$. In order to fill this gap and to assess the performances of "covalent-assembly" type probes bearing a fluoride-sensitive self-immolative linker, we planned the synthesis of fluorescent chemodosimeters 1and 2 (Fig. 2). This entailed us, first, to revisit the synthesis of alkylating agent namely 4-(tertbutyldimethylsilyloxy)benzyl bromide (4-OTBDMS benzyl 
bromide) $\mathbf{3}$, because the published procedures are tedious and time-consuming.

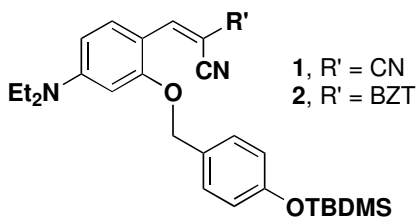

Fig. 2. Self-immolative "covalent-assembly" type probes for $\mathrm{F}^{-}$detection and based on the use of PHBA linker (BZT $=2$-benzothiazolyl, TBDMS $=$ tertbutyldimethylsilyl), targeted in our project.

\section{Revisited synthesis of 4-OTBDMS benzyl bromide 3}

Published synthetic procedures towards 4-OTBDMS benzyl bromide 3 are based on a four-step reaction sequence (Scheme 1, top) [8]. First, selective protection of the phenol of 4hydroxybenzaldehyde with TBDMS-Cl, followed by $\mathrm{NaBH}_{4-}^{-}$ mediated reduction of the formyl moiety provided 4-OTBDMS benzylic alcohol. Next, in order to provide a good leaving group, this alcohol was esterified with trifluoroacetic anhydride (TFAA), and finally this trifluoroacetate underwent nucleophilic reaction with $\mathrm{LiBr}$. This procedure enables obtaining 4OTBDMS benzyl bromide 3 with a satisfactory $40 \%$ yield, yet requires tedious purification steps. To shorten the overall number of steps, we have explored direct and selective silylation of PHBA (phenol vs. primary alcohol) with TBDMS-Cl in the presence of a base (Scheme 1, bottom). Several organic and inorganic bases (i.e., DBU, DIEA, $\mathrm{Cs}_{2} \mathrm{CO}_{3}$ and $\mathrm{K}_{2} \mathrm{CO}_{3}$ ) were tested and DBU appeared to be the best one providing a satisfying $65 \%$ isolated yield. Thereafter, the implementation of Appel reaction (i.e., treatment of alcohol with $\mathrm{CBr}_{4}$ and $\mathrm{PPh}_{3}$ in $\mathrm{MeCN}$ ) enabled the quantitative conversion of 4-OTBDMS benzylic alcohol into the targeted benzyl bromide derivative 3 . However, the poor stability of this latter compound over silica gel prevents its chromatographic isolation in a pure form and with a good yield (only 39\% was obtained). To overcome this issue, we used liquid-liquid extractions with heptane to recover pure 3 and with an acceptable yield of $55 \%$. Its structure was unambiguously confirmed by NMR analyses and comparison with published spectroscopic data (see Supplementary data and Figs. S1 and S2). If the overall yield is slightly lower than the published procedure $(36 \%$ vs. $40 \%)$, this new procedure competes thanks to a lower number of steps and easier purification processes.

With this alkylating reagent in hand, we next examined its reactivity towards 4-(diethylamino)salicylaldehyde with the aim of rapidly synthesizing self-immolative "covalent-assembly" type probes $\mathbf{1}$ and $\mathbf{2}$.

2-O-Alkylation of 4-(diethylamino)salicylaldehyde with 4OTBDMS benzyl bromide 3

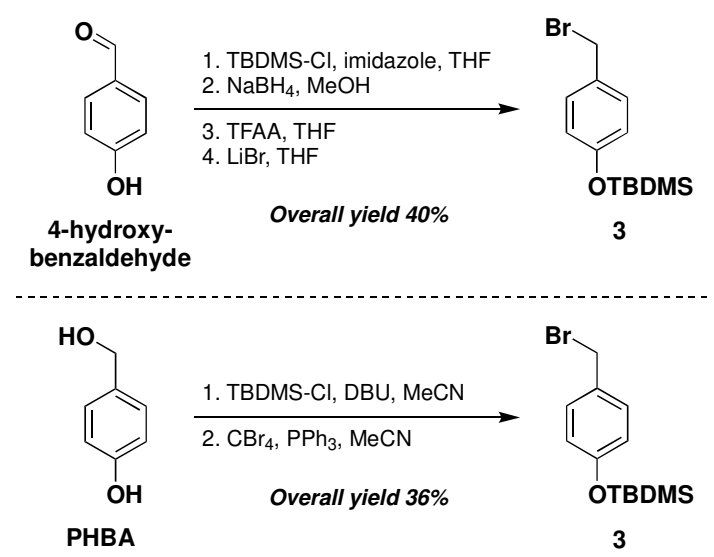

Scheme 1. (Top) Published synthesis of 4-OTBDMS benzyl bromide 3 [8]; (bottom) shortened synthesis of 4-OTBDMS benzyl bromide $\mathbf{3}$ devised by us $(\mathrm{DBU}=$ 1,8-diazabicyclo[5.4.0] undec-7-ene, $\mathrm{TBDMS}-\mathrm{Cl}=$ tertbutyldimethylsilyl chloride, TFAA = trifluoroacetic anhydride).

By analogy with the self-immolative caged precursors of 7(dialkylamino)-(2-imino)coumarins already published, especially those bearing either a 4-(pinacolboronate)benzyl [5p] or a 4nitrobenzyl moiety [5am], reactive towards RNS/ROS and nitroreductase (NTR) enzymes respectively, phenol alkylation of 4-(diethylamino)salicylaldehyde was achieved with 1 equiv. of $\mathbf{3}$, in the presence of $\mathrm{K}_{2} \mathrm{CO}_{3}$ (2 equiv.) as base, in $\mathrm{MeCN}$ and at room temperature (Scheme 2). Surprisingly, this reaction was found to be not univocal with the formation, in addition to the desired benzyl ether $\mathbf{4}$, of an unknown product which was isolated by column chromatography over silica gel in a $10 \%$ to $25 \%$ yield (depending on the reaction attempt and age of benzylation reagent $\mathbf{3}$ ). The same mixture of these two compounds was obtained when $\mathrm{K}_{2} \mathrm{CO}_{3}$ was replaced by $\mathrm{NaH}$ (60\% dispersion in mineral oil). The unknown compound is less polar than 4 but has the same molecular mass as revealed by the HPLC-MS analyses (see Figs. S6, S7, S13 and S14). Thus, two hypothetical structures $\mathbf{5}$ and $\mathbf{6}$ resulting either from quaternarization of the $N, N$-diethylanilino moiety $\left(\mathrm{S}_{\mathrm{N}}\right.$ reaction) or from Friedel-Crafts type alkylation of the electron-rich benzene ring ( $\mathrm{S}_{\mathrm{E}} \mathrm{Ar}$ reaction) can be theoretically put forward. Gratifyingly, a comprehensive NMR study based on 1D and 2D experiments (i.e., COSY and NOESY, see Figs. S11 and S12) confirmed both the lack of aromatic proton $\mathrm{H}-3$, the ortho coupling between protons $\mathrm{H}-5$ and $\mathrm{H}-6(J=8.5 \mathrm{~Hz})$ and the spatial proximity between benzylic methylene protons of 4$O$ TBDMS benzyl moiety and $\mathrm{CH}_{2}$-protons of diethylamino substituent. We may thus conclude that unknown product formed during the $O$-alkylation process is the Friedel-Crafts adduct $\mathbf{6}$. Such C-3-alkyl-substituted 4-(diethylamino)salicylaldehyde derivatives have never been described and their formation under mild conditions as these presented here, is somewhat surprising even if the corresponding benzene ring is electronically enriched by phenolic hydroxyl (deprotonated form in the reaction mixture containing $\mathrm{K}_{2} \mathrm{CO}_{3}$ ) and diethylamino donating groups. Indeed, the sole example of Fridel-Crafts type $\mathrm{C}-2$ benzylation of a 1,3diheterosubstitued benzene was reported by Kumar et al. and it was the reaction between resorcinol (1,3-dihydroxybenzene) and benzyl chloride performed under refluxing xylene $\left(140^{\circ} \mathrm{C}\right)$ for 8 h. In this case, a mixture of mono- (C-2), di- (C-2/C-4) and tribenzyl (C-2/C-4/C-6) adducts in the ratio 6:3:1 was obtained (combined yield 82\%) [9]. The regioselectivity of Friedel-Crafts type alkylation leading to $\mathbf{6}$, is in agreement with the Holleman rules since diethylamino and phenol groups are ortho/para directing and formyl is known to be meta directing group [10]. To gain further information about the possible scope of this 
reaction, we implemented this synthetic procedure with other alkylating agents including 4-nitrobenzyl bromide and 4-(2,4dinitrophenyloxy)benzyl bromide but $O$-alkylation of 4(diethylamino)salicylaldehyde was overwhelmingly observed and only traces of Friedel-Crafts product was detected. This result is consistent with the synthesis of "covalent-assembly" type probes presented above and for which this latter undesired reaction was never mentioned. One possible interpretation of this peculiar reactivity is that the formation of benzyl-type carbocation (the reactive intermediate required for $\mathrm{S}_{\mathrm{E}} \mathrm{Ar}$ reactions on salicylaldehyde derivative) is favored only in the case 4$O$ TBDMS benzyl bromide due to the electron-donating ability of its para-substituent (i.e., $+\mathrm{M}$ effect of the silyloxy group $v s$. -M effect of nitro and 2,4-dinitrophenyloxy moieties). Also noteworthy and in agreement with our hypotheses, is that when we assayed the reaction of 4-(diethylamino)salicylaldehyde with 4-OTBDMS benzyl alcohol under Mitsunobu conditions (i.e., treatment with $\mathrm{PPh}_{3}$ and DIAD in $\mathrm{Et}_{2} \mathrm{O}$ ) [11] the sole observed product was $O$-alkylated product 4.

To check the reactivity of the salicylaldehyde part of the molecule 6 and to access to novel 7-(diethylamino)coumarins, we have then explored its condensation with malononitrile and benzothiazole-2-acetonitrile.
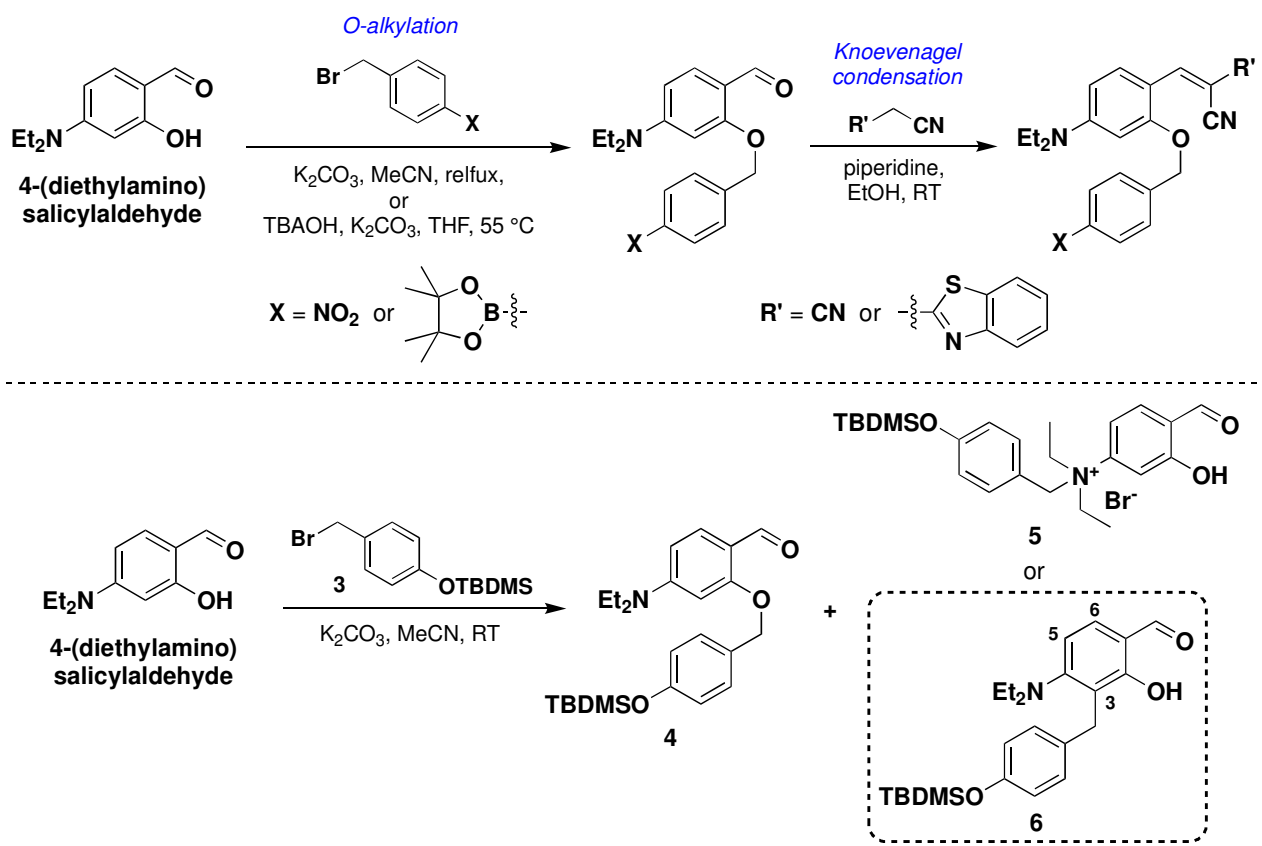

Scheme 2. (Top) Published syntheses of NTR- and peroxynitrite-responsive self-immolative "covalent-assembly" type probes based on $O$-alkylation of 4(diethylamino)salicylaldehyde with 4-nitrobenzyl bromide or 4-(pinacolboronate)benzyl bromide and subsequent Knoevenagel condensation reaction $(\mathrm{TBAOH}=$ tetrabutylammonium hydroxyde) [5p],[5am]; (bottom) alkylation of 4-(diethylamino)salicylaldehyde with 4-OTBDMS benzyl bromide 3 leading to unexpected Friedel-Crafts alkylation product 6.

\section{Synthesis of 8-substituted-7-(diethylamino)coumarins 7 and 8}

The synthesis of both coumarins $\mathbf{7}$ and $\mathbf{8}$, through Knoevenagel condensation reaction, was achieved under conventional conditions: treatment with C-nucleophile (1 equiv.), in the presence of piperidine ( 1 equiv.) and anhydrous $\mathrm{Na}_{2} \mathrm{SO}_{4}(2$ equiv.), in EtOH at room temperature (Scheme 3). Purification by column chromatography over silica gel provided the 7(diethylamino)coumarins $\mathbf{7}$ and $\mathbf{8}$ in a satisfying 60\% yield even if an additional purification by trituration with $\mathrm{MeOH}$ was required to recover 7 in a pure form. It is important to note that the hydrolysis of imine moiety (this two-step Knoevenagelcyclization sequence actually leads to 2-iminocoumarin derivatives) occurred during the purification process.

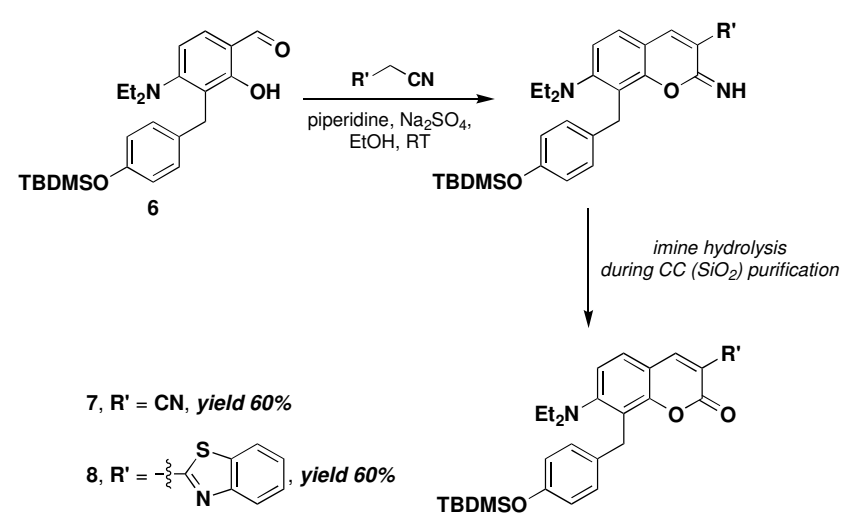

Scheme 3. Synthesis of 8-substituted 7-(diethylamino)coumarin dyes $\mathbf{7}$ and $\mathbf{8}$ $\left(\mathrm{CC}\left(\mathrm{SiO}_{2}\right)=\right.$ column chromatography over silica gel $)$.

In order to assess the effect of 4-OTBDMS benzyl moiety on photophysical properties of theses novel 7(diethylamino)coumarin derivatives, we have also prepared the parent compounds 9 and $\mathbf{1 0}$ lacking this C-8 substituent (Scheme 4). 3-Cyano-7-(diethylamino)coumarin 9 was prepared from 4(diethylamino)salicylaldehyde and ethyl cyanoacetate, according 
to a literature procedure [12]. As for the Knoevenagel condensation with 2-(2-benzothiazolyl)acetic acid ethyl ester, reaction time was dramatically shortened using microwave irradiation $\left(20 \mathrm{~min}\right.$ at $160{ }^{\circ} \mathrm{C}$ vs. $6 \mathrm{~h}$ under refluxing $\mathrm{MeOH}$ [13]), and purification by column chromatography provided $\mathbf{1 0}$ with a good $87 \%$ yield. For these four compounds, all spectroscopic data, especially IR, NMR and mass spectrometry, were in agreement with the structures assigned (see Supplementary data).

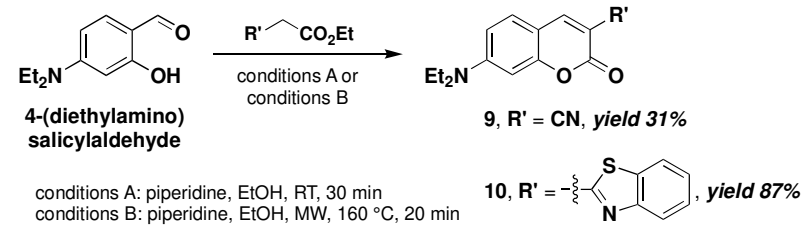

Scheme 4. Synthesis of 7-(diethylamino)coumarin dyes $\mathbf{9}$ and $\mathbf{1 0}(\mathrm{MW}=$ microwave irradiation)

\section{Photophysical characterization of DEAC-based fluorophores}

The photophysical properties of synthesized 7(diethylamino)coumarins 7-10 were evaluated in DMSO (solvent in which these compounds are perfectly soluble and used for the preparation of their stock solutions), in $\mathrm{EtOH}$ and in phosphatebuffered saline (PBS, pH 7.5) which mimics physiological conditions. Fluorophores 7-10 were found to be perfectly soluble in PBS only at low concentrations (less than $5 \mu \mathrm{M}$ ). At higher concentrations, light scattering by suspension was clearly observed on UV-vis absorption spectra (Fig. 3C and Figs. S21, S22, S32, S33, S36 and S39). All results are compiled in Table 1 (see Fig. 3 for the absorption/fluorescence spectra of $\mathbf{8}$ and Supplementary data for the absorption/fluorescence spectra of compounds 7, 9 and 10). In polar organic solvents (DMSO and EtOH), the C-8 substitution of DEAC scaffold caused the broadening and dramatic blue-shift of the absorption band, quite probably because the formation of aggregates especially in the case of derivative $\mathbf{8}$ which bears the hydrophobic benzothiazolyl C-3 substituent (e.g., $\Delta \lambda_{1 / 2 \max }$ values: $89-93 \mathrm{~nm}$ for $\mathbf{8} v$ s. $64-65$ $\mathrm{nm}$ for its C-8 unsubstituted counterpart 10). The lack of a significant blue-green fluorescence emission upon excitation at $410 \mathrm{~nm}\left(\Phi_{\mathrm{F}}=1-2 \%\right)$, confirms the preponderance of non- emissive species in solution and a possible radiation less deexcitation pathway caused by rotational motions of 4-OTBDMS benzyl moiety. The spectral signature in aq. buffer (PBS) is somewhat different because $\mathbf{7}$ and $\mathbf{8}$ exhibit a wide emission band ranging from 500 to $700 \mathrm{~nm}$ (centered at ca. $560 \mathrm{~nm}$ ) which is consistent with the behavior described by an aggregation-induced emission (AIE) effect [14].
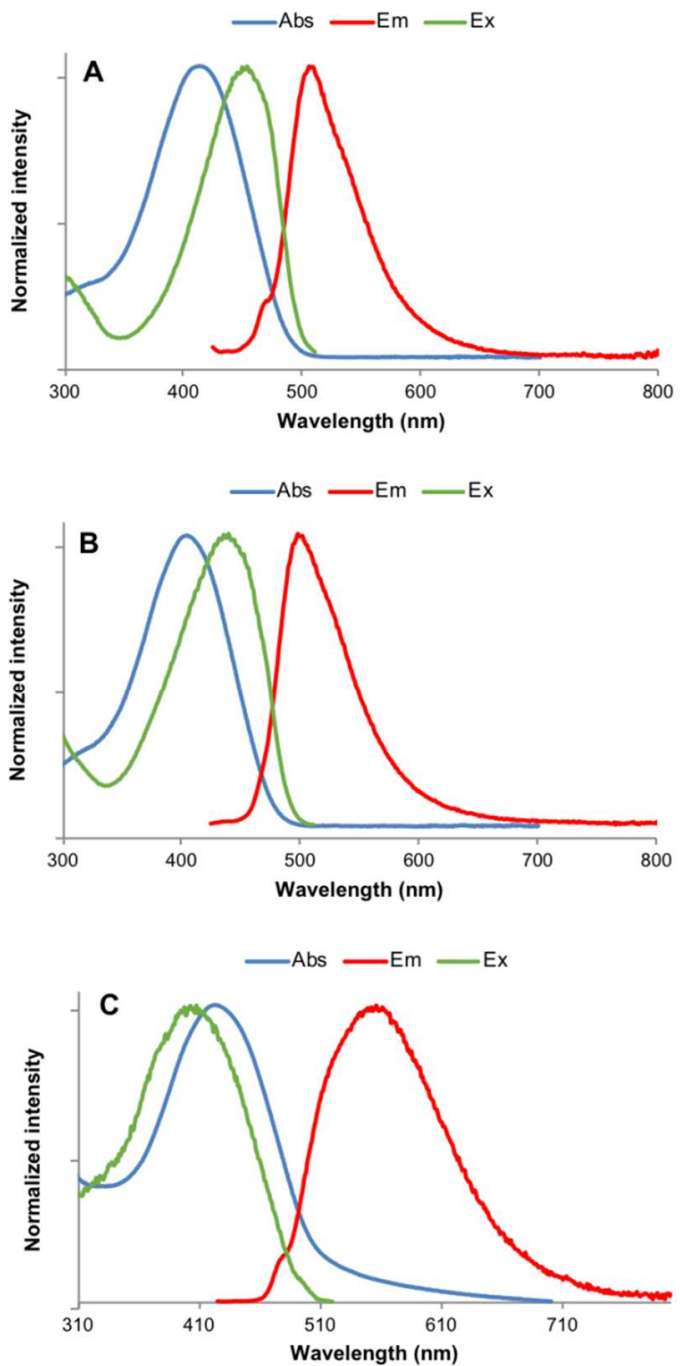

Fig. 3. Normalized absorption (blue), excitation (Em. 525 or $600 \mathrm{~nm}$, slit 5 $\mathrm{nm}$, green) and emission (Ex. $410 \mathrm{~nm}$, slit $5 \mathrm{~nm}$, red) spectra of coumarin 8 in DMSO (A), EtOH (B) and PBS (C) at $25{ }^{\circ} \mathrm{C}$. Please note: the recorded absorption spectrum of 8 in $P B S$ is due both to light scattering (by aggregates) and absorption.

To confirm this property, the fluorescence behavior of $\mathbf{7}$ and 8 in water/EtOH mixtures was studied. As displayed in Fig. 4, in pure $\mathrm{EtOH}, 8$ shows weak fluorescence centered at $500 \mathrm{~nm}$. When water fraction varies from $10 \%$ to $50 \%$, the emission marginally decreases but without alterations in the shape of emission curve. This is probably related to the aggregationcaused quenching (ACQ) effect. When the fraction of water is greater than $50 \%$, the emission maximum peak red shifts to 560 $\mathrm{nm}$ along with a fluorescence intensity increase evidently. 
Table 1

Photophysical properties of DEAC-based fluorophores studied in this work, determined at $25^{\circ} \mathrm{C}$.

\begin{tabular}{|c|c|c|c|c|c|c|}
\hline $\mathrm{Cmpd}^{a}$ & Solvent & $\lambda_{\max } \operatorname{Abs}(\mathrm{nm})$ & $\lambda_{\max } \operatorname{Em}(\mathrm{nm})$ & $\Delta \lambda_{1 / 2 \max }(\mathrm{nm})$ & $\varepsilon\left(\mathrm{M}^{-1} \mathrm{~cm}^{-1}\right)$ & $\Phi_{\mathrm{F}}(\%)^{b}$ \\
\hline 7 & PBS, pH 7.5 & 419 & 561 & 90 & 17700 & 2 \\
\hline 7 & DMSO & 411 & 468 & 88 & 16300 & $--^{c}$ \\
\hline 7 & $\mathrm{EtOH}$ & 405 & 467 & 76 & 16400 & $-^{c}$ \\
\hline 8 & PBS, pH 7.5 & 423 & 556 & 112 & 20550 & 7 \\
\hline 8 & DMSO & 414 & 506 & 93 & 23800 & 1.5 \\
\hline 8 & $\mathrm{EtOH}$ & 405 & 502 & 89 & 22900 & 2 \\
\hline 9 & PBS, pH 7.5 & 352,431 & 479 & $-d$ & 12200,6000 & $-^{c}$ \\
\hline 9 & $\begin{array}{l}\mathrm{PBS}+5 \% \mathrm{EtOH}, \\
\mathrm{pH} 7.5\end{array}$ & 352,431 & 479 & $-d$ & 10700,7100 & 1.5 \\
\hline 9 & DMSO & 430 & 478 & 49 & 46600 & 3.5 \\
\hline 9 & $\mathrm{EtOH}$ & 423 & 467 & 49 & 46900 & 3 \\
\hline 10 & PBS, pH 7.5 & 463,498 & 557 & $-{ }^{d}$ & 17200,18000 & 2.5 \\
\hline 10 & DMSO & 468 & 516 & 65 & 56400 & 67 \\
\hline 10 & $\mathrm{EtOH}$ & 459 & 503 & 64 & 54100 & 75 \\
\hline
\end{tabular}

${ }^{\text {a }}$ Stock solutions $(1.0 \mathrm{mg} / \mathrm{mL})$ of fluorophores were prepared in DMSO.

${ }^{\mathrm{b}}$ Determined using coumarin 153 as a standard $\left(\Phi_{\mathrm{F}}=38 \%\right.$ in EtOH, Ex. at $\left.410 \mathrm{~nm}\right)$ except for 7 in PBS, $\mathrm{Ru}(\mathrm{bpy})_{3} \mathrm{Cl}_{2}$ was used in this case $\left(\Phi_{\mathrm{F}}=2.8 \%\right.$ in water saturated with air, Ex. at $410 \mathrm{~nm}$ ) [15].

${ }^{\mathrm{c}}$ Very low or no fluorescence.

${ }^{\mathrm{d}}$ Not determined due to the presence of two maxima.

As water is a poor solvent of $\mathbf{8}$, the addition of water would induce the formation of aggregates, that hinders the intramolecular rotational motions of 4-OTBDMS benzyl moiety, thus blocking the non-radiative relaxation pathways and boosting the yellow-orange emission (i.e., restriction of intramolecular rotations (RIR) mechanism) [14]. Moreover, the fluorescence quantum yield of $\mathbf{8}$ in the solid state was measured to be $7 \%$ for an emission maximum centered at $534 \mathrm{~nm}$ (see Supplementary data for experimental details related to the determination of solid state absolute fluorescence quantum yields and Figs. S41-S44). The same behavior was observed with the less hydrophobic 3cyano derivative 7 but the formation of strongly emissive aggregates was occurred at a higher fraction of water in $\mathrm{EtOH}$ $(>70 \%)$ (Fig. S45). As expected, this AIE effect was found to be negligible in the case of parent C-8 unsubstituted 7(diethylamino)coumarins 9 and $\mathbf{1 0}$ (Fig. 4 and Fig. S45). Indeed, the shape and position of the fluorescence emission spectrum of 3-cyano derivative 9 are similar whatever the solvent used for the spectral measurements. The fluorescence quantum yield is also in the same order of magnitude. For its part, the 3-(2benzothiazolyl) derivative $\mathbf{1 0}$ emits intense green light both in DMSO and in EtOH ( $\Phi_{\mathrm{F}}=67 \%$ and $75 \%$ respectively), but its dissolution in PBS causes a large bathochromic shift in the emission color with an almost complete quenching of its fluorescence $\left(\Phi_{\mathrm{F}}=2.5 \%\right)$. These features are consistent with an ACQ effect instead of AIE characteristics displayed by this more hydrophobic derivative. To clarify which rotors of 4-OTBDMS benzyl moiety are responsible for the AIE effect, we have finally synthesized (i.e., aq. TFA deprotection of TBDMS ether of $\mathbf{8}$ ) and studied photophysical properties of the 8-(4-hydroxybenzyl) derivative 11. This compound displays the same spectral features and AIE behavior than that for 8 (Fig. 4 and Figs. S39 and S40), even if the fluorescence emission efficiency of aggregates in water is lower $\left(\Phi_{\mathrm{F}} 2 \%\right.$ vs. $7 \%$ for $\left.\mathbf{8}\right)$. These results may indicate that the AIE activity of $\mathbf{7}$ and $\mathbf{8}$ is mainly ascribed to rotational motions of the benzyl moiety and not those of silyl group.

To the best of our knowledge, few works have already described the facile functionalization of $2 \mathrm{H}$-chromen-2-one scaffold with AIE-active moieties to generate coumarin-based AIE fluorophores with long-wavelength emission. Worth mentioning in this context are 7-(diethylamino)coumarin or 4methylumbelliferone Schiff base derivatives bearing an AIEactive substituent connected to $\mathrm{C}-3$ or $\mathrm{C}-8$ position via an imine linkage [16]. Some of them have been used as fluorescent probes for effective detection of biothiols (cysteine) or heavy metal cations such as $\mathrm{Hg}(\mathrm{II})$ [16a, 16b].
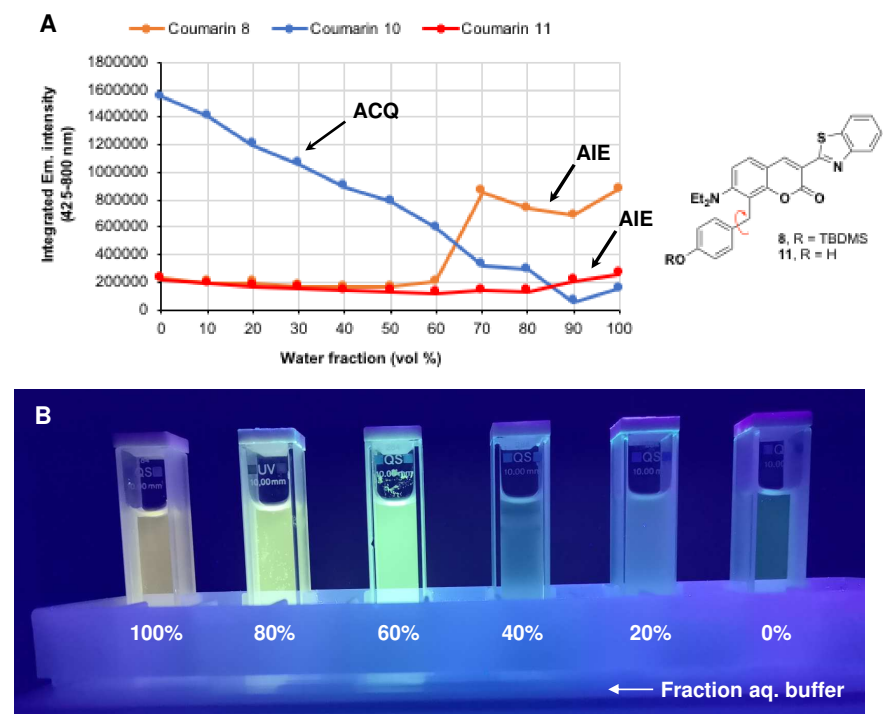

Fig. 4. Demonstration of AIE properties of 8-substituted 3-(2benzothiazolyl)-7-(diethylamino)coumarin 8. (A, left) Fluorescence emission (integrated between 425 and $800 \mathrm{~nm}$ ) of $\mathbf{8 , 1 0}$ and $11 \mathrm{vs}$. water fraction in $\mathrm{EtOH} /$ water mixtures (concentration $=1.0 \mu \mathrm{M}$, Ex. at $410 \mathrm{~nm}, \mathrm{Em} .425-800$ $\mathrm{nm}$, Ex./Em. slit $=5 \mathrm{~nm}$ for 8 and 11 and $2 \mathrm{~nm}$ for 10); (A, right) schematic representation of intramolecular rotations in coumarins $\mathbf{8}$ and 11; (B) Photographs of $8(15 \mu \mathrm{M})$ in $\mathrm{PB} / \mathrm{EtOH}$ (fraction aq. buffer vol\%) mixtures taken under $365 \mathrm{~nm}$ UV illumination ( $\mathrm{PB}=$ phosphate buffer, $100 \mathrm{mM}, \mathrm{pH}$ 7.6). Please note: for the recording of Em. spectra, water was used instead of $P B$ to avoid interferences causing by partial precipitation of phosphate salts in EtOH as observed in Fig. 4B. Suspension observed in quartz cells (Fig. $4 B)$ was due to phosphate salts precipitation at low fractions of aq. buffer, and to partial precipitation of coumarin 8 at high fractions of aq. buffer. 
In summary, we have reported our findings related to the unprecedented C-3 functionalization of 4(diethylamino)salicylaldehyde through a Friedel-Crafts alkylation reaction conducted under mild conditions and with electron-rich 4-OTBDMS benzyl bromide 3. This unusual reaction is not applicable to a wide range of para-substituted benzyl bromide derivatives, especially those currently employed for the synthesis of self-immolative fluorescent probes for (bio)sensing purposes. However, the availability of unusual salicylaldehyde derivative 6 has enabled us to prepare two novel 7-(diethylamino)coumarins through conventional Knoevenagel reaction. A comprehensive photophysical study of these fluorophores led both to the discovery of their AIE properties and the identification of 4$O T B D M S$ benzyl as a novel AIE-active moiety. The conversion of conventional 7-(diethylamino)coumarin dyes to AIE fluorophores is thus realized by a simple transformation (FriedelCrafts alkylation), avoiding laborious and more complex synthetic operations sometimes associated with the incorporation of popular AIE-active moieties (e.g., tetraphenylethylene, TPE) onto fluorescent scaffolds $[14,17]$. We are confident that this strategy and others related could be applied to the introduction of benzyl-type rotors onto fluorophores for which some positions reactive towards electrophiles are clearly identified (e.g., C-4/C-5 and possibly $\mathrm{C}-2 / \mathrm{C}-7$ positions of xanthene dyes including fluoresceins, pyronins and rhodamines). Lastly, the identification of some 8-substituted 7-hydroxycoumarin derivatives as potent $\alpha$-amylase inhibitors [9], could maybe lead medicinal chemists to assess the potential of the reported Friedel-Crafts type reaction for facile preparation of coumarin-based antidiabetic agents [18].

\section{Acknowledgments}

This work is supported by the CNRS, Universite de Bourgogne and Conseil Régional de Bourgogne through the "Plan d'Actions Régional pour l'Innovation (PARI) and the "Fonds Européen de Développement Régional (FEDER)" programs. B. R. gratefully acknowledges the "Région-Haute Normandie" for his Ph. D. grant (2012-2015). Financial support from Agence Nationale de la Recherche (ANR, AAPG 2018, DetectOP_BChE, ANR-18CE39-0014), especially for the post-doc fellowship of V. Q. is also greatly acknowledged, as well as Labex SynOrg (ANR-11LABX-0029). The authors thank the "Plateforme d'Analyse Chimique et de Synthèse Moléculaire de l'Université de Bourgogne" (PACSMUB, http://www.wpcm.fr) for access to spectroscopy instrumentation and Iris Biotech company for the generous gift of some chemical reagents used in this work. The authors also thank Marcel Soustelle (University of Burgundy, ICMUB, UMR CNRS 6302) for elemental analyses, Prof. Ewen Bodio (University of Burgundy, ICMUB, UMR CNRS 6302, OCS team) for access to SAFAS Flx-Xenius XC spectrofluorimeter (equipped with a $\mathrm{BaSO}_{4}$ integrating sphere), Dr. Jean-Franck Bussotti / M. Olivier Chaudon (SAFAS Monaco company) for their precious advice regarding the determination of absolute fluorescence quantum yields, and Drs. Kévin Renault and Ibai E. Valverde (ICMUB, UMR CNRS 6302) for helpful discussions and relevant comments on this manuscript before publication.

\section{Supplementary data}

Supplementary data (all synthetic procedures, spectroscopic and photophysical characterizations of fluorophores described in this work) associated with this article can be found, in the online version:

\section{References and note}

A preprint was previously posted on ChemRxiv, see https://doi.org/10.26434/chemrxiv.9742688.v1.

[1] For comprehensive reviews, see: a) H. E. Katerinopoulos, Curr. Pharm. Des. 10 (2004) 3835-3852; b) H. Li, L. Cai, Z. Chen In Advances in Chemical Sensors; InTech, 2011. pp 121150; c) D. Cao, Z. Liu, P. Verwilst, S. Koo, P. Jangjili, J. S. Kim, W. Lin, Chem. Rev. 119 (2019) 10403-10519.

[2] a) Q. Wu, E. V. Anslyn, J. Mater. Chem. 15 (2005) 28152819; b) E. V. Anslyn, J. Am. Chem. Soc. 132 (2010) 1583315835; c) Y. Yang, S. K. Seidlits, M. M. Adams, V. M. Lynch, C. E. Schmidt, E. V. Anslyn, J. B. Shear, J. Am. Chem. Soc. 132 (2010) 13114-13116.

[3] For reviews on "covalent-assembly" type probes, see: a) A. Romieu, Org. Biomol. Chem. 13 (2015) 1294-1306; b) T. He, H. He, X. Luo, Y. Yang, Y. Yang, Sci. Sinica Chim. 47 (2017) 945954.

[4] T.-H. Kim, T. M. Swager, Angew. Chem. Int. Ed. 42 (2003) 4803-4806.

[5] a) W. Jiang, W. Wang, Chem. Commun. (2009) 3913-3915; b) J. H. Do, H. N. Kim, J. Yoon, J. S. Kim, H.-J. Kim, Org. Lett. 12 (2010) 932-934; c) T.-I. Kim, M. S. Jeong, S. J. Chung, Y. Kim, Chem. - Eur. J. 16 (2010) 5297-5300; d) T.-I. Kim, H. Kim, Y. Choi, Y. Kim, Chem. Commun. 47 (2011) 9825-9827; e) D. Kim, S. Sambasivan, H. Nam, K. Hean Kim, J. Yong Kim, T. Joo, K.-H. Lee, K.-T. Kim, K. Han Ahn, Chem. Commun. 48 (2012) 6833-6835; f) D. Kim, S. Singha, T. Wang, E. Seo, J. H. Lee, S.-J. Lee, K. H. Kim, K. H. Ahn, Chem. Commun. 48 (2012) 10243-10245; g) I. Kim, D. Kim, S. Sambasivan, K. H. Ahn, Asian J. Org. Chem. 1 (2012) 60-64; h) H. Mohapatra, S. T. Phillips, Angew. Chem. Int. Ed. 51 (2012) 11145-11148; i) Y. Peng, Y.-M. Dong, M. Dong, Y.-W. Wang, J. Org. Chem. 77 (2012) 9072-9080; j) J. Park, Y. Kim, Bioorg. Med. Chem. Lett. 23 (2013) 2332-2335; k) P. Hou, S. Chen, H. Wang, J. Wang, K. Voitchovsky, X. Song, Chem. Commun. 50 (2014) 320-322; 1) J. Kim, J. Park, H. Lee, Y. Choi, Y. Kim, Chem. Commun. 50 (2014) 9353-9356; m) C. Wang, S. Yang, M. Yi, C. Liu, Y. Wang, J. Li, Y. Li, R. Yang, ACS Appl. Mater. Interfaces 6 (2014) 9768-9775; n) J.-T. Yeh, P. Venkatesan, S.-P. Wu, New J. Chem. 38 (2014) 6198-6204; o) S. Zhang, J. Fan, S. Zhang, J. Wang, X. Wang, J. Du, X. Peng, Chem. Commun. 50 (2014) 14021-14024; p) J. Zhou, Y. Li, J. Shen, Q. Li, R. Wang, Y. Xu, X. Qian, RSC Adv. 4 (2014) 51589-51592; q) S. Debieu, A. Romieu, Org. Biomol. Chem. 13 (2015) 10348-10361; r) Q. Fang, Q. Liu, X. Song, J. Kang, Luminescence 30 (2015) 12801284; s) Y. Han, C. Yang, K. Wu, Y. Chen, B. Zhou, M. Xia, RSC Adv. 5 (2015) 16723-16726; t) P. K. Mishra, T. Saha, P. Talukdar, Org. Biomol. Chem. 13 (2015) 7430-7436; u) H. Mohapatra, H. Kim, S. T. Phillips, J. Am. Chem. Soc. 137 (2015) 12498-12501; v) G. Zhang, Y. Sun, X. He, W. Zhang, M. Tian, R. Feng, R. Zhang, X. Li, L. Guo, X. Yu, S. Zhang, Anal. Chem. 87 (2015) 12088-12095; w) H. Zhang, Y. Xie, P. Wang, G. Chen, R. Liu, Y.-W. Lam, Y. Hu, Q. Zhu, H. Sun, Talanta 135 (2015) 149-154; x) J. Zhang, Y. Li, W. Guo, Anal. Methods 7 (2015) 4885-4888; y) Y. Chen, B. Chen, D. Luo, Y. Cai, Y. Wei, Y. Han, Tetrahedron Lett. 57 (2016) 1192-1195; z) Y. Chen, M. Zhang, Y. Han, J. Wei, RSC Adv. 6 (2016) 8380-8383; aa) A. K. Das, S. Goswami, C. K. Quah, H.-K. Fun, RSC Adv. 6 (2016) 18711-18717; ab) Z. Hu, J. Hu, H. Wang, Q. Zhang, M. Zhao, C. Brommesson, Y. Tian, H. Gao, X. Zhang, K. Uvdal, Anal. Chim. Acta 933 (2016) 189-195; ac) D. Kim, S.-Y. Na, H.-J. Kim, Sens. 
Actuators B-Chem. 226 (2016) 227-231; ad) X. Liu, F. Qi, Y. $\mathrm{Su}, \mathrm{W}$. Chen, L. Yang, X. Song, J. Mater. Chem. C 4 (2016) 4320-4326; ae) X. Liu, D. Yang, W. Chen, L. Yang, F. Qi, X. Song, Sens. Actuators B-Chem. 234 (2016) 27-33; af) F. Qi, X. Liu, L. Yang, L. Yang, W. Chen, X. Song, Tetrahedron 72 (2016) 6909-6913; ag) J. Zhang, Y. Li, J. Zhao, W. Guo, Sens. Actuators B-Chem. 237 (2016) 67-74; ah) W. Chen, X. Yue, W. Li, Y. Hao, L. Zhang, L. Zhu, J. Sheng, X. Song, Sens. Actuators BChem. 245 (2017) 702-710; ai) M. A. Miller, B. Askevold, H. Mikula, R. H. Kohler, D. Pirovich, R. Weissleder, Nat. Commun. 8 (2017) 15906; aj) J. Hu, T. Liu, H.-W. Gao, S. Lu, K. Uvdal, Z. Hu, Sens. Actuators B-Chem. 269 (2018) 368-376; ak) B. Huo, M. Du, A. Gong, M. Li, L. Fang, A. Shen, Y. Lai, X. Bai, Y. Yang, Anal. Methods 10 (2018) 3475-3480; al) Y. Kim, M. Choi, S. V. Mulay, M. Jang, J. Y. Kim, W.-h. Lee, S. Jon, D. G. Churchill, Chem. - Eur. J. 24 (2018) 5623-5629; am) X. Liu, L. He, L. Yang, Y. Geng, L. Yang, X. Song, Sens. Actuators BChem. 259 (2018) 803-808; an) L. Xia, F. Hu, J. Huang, N. Li, Y. Gu, P. Wang, Sens. Actuators B-Chem. 268 (2018) 70-76; ao) L. Yang, Y. Su, Y. Geng, H. Xiong, J. Han, Q. Fang, X. Song, Org. Biomol. Chem. 16 (2018) 5036-5042; ap) L. Yang, Y. Su, Z. Sha, Y. Geng, F. Qi, X. Song, Org. Biomol. Chem. 16 (2018) 1150-1156; aq) W. Li, S. Zhou, L. Zhang, Z. Yang, H. Chen, W. Chen, J. Qin, X. Shen, S. Zhao, Sens. Actuators B-Chem. 284 (2019) 30-35; ar) Y. Liu, W. Yan, H. Li, H. Peng, X. Suo, Z. Li, H. Liu, J. Zhang, S. Wang, D. Liu, Anal. Methods 11 (2019) 421426; as) H. Qin, L. Li, K. Li, Y. Xiaoqi, Chin. Chem. Lett. 30 (2019) 71-74; at) J. Wang, C. Li, Q. Chen, H. Li, L. Zhou, X. Jiang, M. Shi, P. Zhang, G. Jiang, B. Z. Tang, Anal. Chem. 91 (2019) 9388-9392; au) L. Yang, Y. Liu, Y. Li, H. Wang, H. Zhang, J. Xu, L. Ji, Q. Wang, G. He, Tetrahedron 75 (2019) Article 130538.

[6] J. Yan, S. Lee, A. Zhang, J. Yoon, Chem. Soc. Rev. 47 (2018) 6900-6916.

[7] For selected application examples, see: a) E. K. Y. Chen, R. A. McBride, E. R. Gillies, Macromolecules 45 (2012) 73647374; b) H.-J. Jin, J. Lu, X. Wu, Bioorg. Med. Chem. 20 (2012) 3465-3469; c) S. Park, S. Y. Kim, J. Cho, D. Jung, D. Seo, J. Lee, S. Lee, S. Yun, H. Lee, O. Park, B. Seo, S. Kim, M. Seol, S. H. Woo, T. K. Park, Bioconjugate Chem. 30 (2019) 1969-1978. [8] a) K. Kopka, A. Faust, P. Keul, S. Wagner, H.-J. Breyholz, C. Höltke, O. Schober, M. Schäfers, B. Levkau, J. Med. Chem. 49 (2006) 6704-6715; b) J. Wu, R. Huang, T. Wang, X. Zhao, W. Zhang, X. Weng, T. Tian, X. Zhou, Org. Biomol. Chem. 11 (2013) 2365-2369.

[9] J. A. Kumar, A. K. Tiwari, G. Saidachary, D. A. Kumar, Z. Ali, B. Sridhar, B. C. Raju, Med. Chem. 9 (2013) 806-811.

[10] A. F. Holleman, Chem. Rev. 1 (1924) 187-230.
[11] D. Liu, L. P. Sanow, C. Zhang, Tetrahedron Lett. 55 (2014) 3090-3092.

[12] J. Volmajer, R. Toplak, I. Leban, A. M. L. Marechal, Tetrahedron 61 (2005) 7012-7021.

[13] J.-A. Cheng, C.-P. Chang, C.-H. Chen, M.-S. Lin, J. Polym. Res. 12 (2005) 53-59.

[14] For comprehensive reviews on AIE, see: a) J. Mei, N. L. C. Leung, R. T. K. Kwok, J. W. Y. Lam, B. Z. Tang, Chem. Rev. 115 (2015) 11718-11940; b) Y. Hong, Methods Appl. Fluoresc. 4 (2016) 022003; c) L. Mao, Y. Liu, S. Yang, Y. Li, X. Zhang, Y. Wei, Dyes Pigm. 162 (2019) 611-623.

[15] A. M. Brouwer, Pure Appl. Chem. 83 (2011) 2213-2228.

[16] a) G. Zhang, X. Zhang, Y. Zhang, H. Wang, L. Kong, Y. Tian, X. Tao, H. Bi, J. Yang, Sens. Actuators B-Chem. 221 (2015) 730-739; b) L. Yan, Z. Kong, W. Shen, W. Du, Y. Zhou, Z. Qi, RSC Adv. 6 (2016) 5636-5640; c) L. Q. Yan, Z. N. Kong, Y. Xia, Z. J. Qi, New J. Chem. 40 (2016) 7061-7067; d) L. Yan, R. Li, W. Shen, Z. Qi, J. Lumin. 194 (2018) 151-155.

[17] For examples of fluorophore functionalization with TPE moiety, see: a) J. Wang, S. Xia, J. Bi, M. Fang, W. Mazi, Y. Zhang, N. Conner, F.-T. Luo, H. P. Lu, H. Liu, Bioconjugate Chem. 29 (2018) 1406-1418; b) X. Zhao, Y. Chen, G. Niu, D. Gu, J. Wang, Y. Cao, Y. Yin, X. Li, D. Ding, R. Xi, M. Meng, ACS Appl. Mater. Interfaces 11 (2019) 13134-13139.

[18] H. Li, Y. Yao, L. Li, J. Pharm. Pharmacol. 69 (2017) 12531264.

\section{Graphical Abstract}

To create your abstract, type over the instructions in the template box below. Fonts or abstract dimensions should not be changed or altered. 


\begin{tabular}{|c|c|}
\hline $\begin{array}{l}\text { Reinvestigation of the synthesis of "covalent- } \\
\text { assembly" type probes for fluoride ion } \\
\text { detection. Identification of novel 7- } \\
\text { (diethylamino)coumarins with aggregation- } \\
\text { induced emission properties }\end{array}$ & Leave this area blank for abstract info. \\
\hline Valentin Quesneau, Benoît Roubinet, Pierre-Yves Re & omso \\
\hline
\end{tabular}

